\title{
Sustainable porous polymer catalyst for size-selective cross-coupling reactions
}

Sungyoon $\mathrm{Kim}^{\dagger}$, Byoungkook Kim${ }^{\ddagger}$ Nesibe A. Dogan§ and Cafer T. Yavuz,

†Department of Chemistry, Korea Advanced Institute of Science and Technology (KAIST), Daehak-ro 291, Yuseong-gu, Daejeon 34141, Republic of Korea.

$\ddagger K A I S T$ Analysis Center for Research Advancement, Korea Advanced Institute of Science and Technology (KAIST), Daehak-ro 291, Yuseong-gu, Daejeon 34141, Republic of Korea.

$\S$ Department of Chemical and Biomolecular Engineering, Korea Advanced Institute of Science and Technology (KAIST), Daehak-ro 291, Yuseong-gu, Daejeon 34141, Republic of Korea.

IGraduate School of EEWS, Korea Advanced Institute of Science and Technology (KAIST), Daehak-ro 291, Yuseong-gu, Daejeon 34141, Republic of Korea.

*Correspondence email: yavuz@kaist.ac.kr 


\section{Contents}

Figure S1. TGA curves of COP-220 under air (black) or $\mathrm{N}_{2}$ (red) flow.

Figure S2. Powder X-ray diffraction pattern of COP-220

Figure S3. Argon physisorption isotherms of COP-220 at $77 \mathrm{~K}$. Relative equivalence of 1,4-diethynylbenzene compared to erythrosine B is shown: 2eq (black), 3eq (red), and 4 eq (blue). Argon gas uptake was measured at $77 \mathrm{~K}$ for better observation of microporous properties.

Figure S4. Solid-state ${ }^{31} \mathrm{P}$ NMR spectra of $(\mathrm{a})$ phosphoric acid $\left(\mathrm{H}_{3} \mathrm{PO}_{4}\right)$ as a reference, (b) triphenylphosphine $\left(\mathrm{PPh}_{3}\right)$, (c) bis(triphenylphosphine)palladium(II) dichloride $\left(\mathrm{Pd}\left(\mathrm{PPh}_{3}\right)_{2} \mathrm{Cl}_{2}\right)$, and (d) triphenylphosphine oxide $\left(\mathrm{Ph}_{3} \mathrm{PO}\right)$.

Figure S5. (a) Calculated Rouquerol plot for COP-220 (Inset: enlarged plot) along with the pressure ranges used for the BET surface area calculations. We have used the pressure range where the term $V\left(1-P / P_{0}\right)$ continuously increases with $P / P_{0}$ for the surface area calculations. (b) The selected points are located in the pressure ranges of 0.01 to 0.12 according to the Rouquerol plots. The data points from BET plot of COP-220 obtained from nitrogen isotherms at $77 \mathrm{~K}$ are used. 


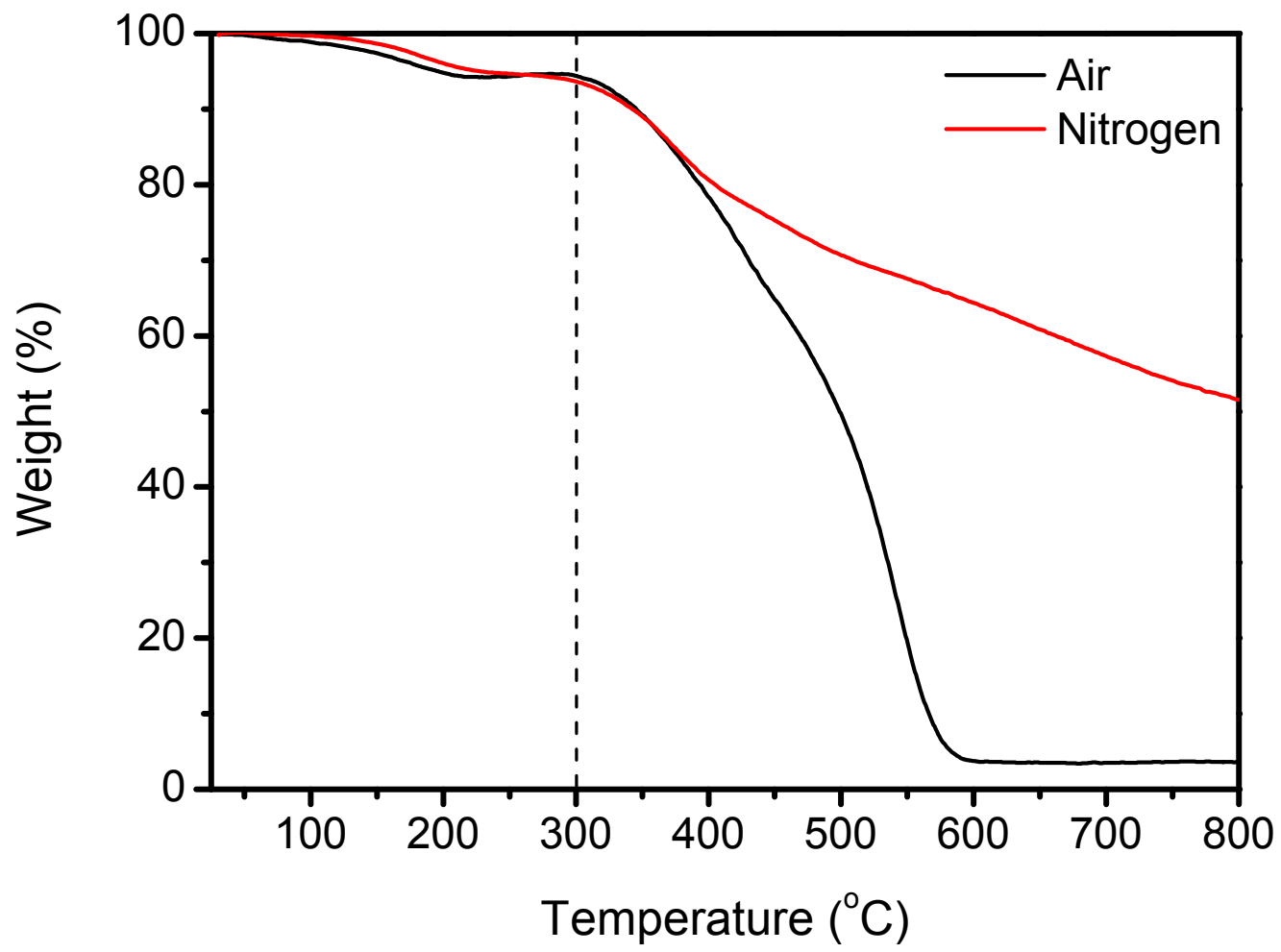

Figure S1. TGA curves of COP-220 under air (black) or $\mathrm{N}_{2}$ (red) flow. 


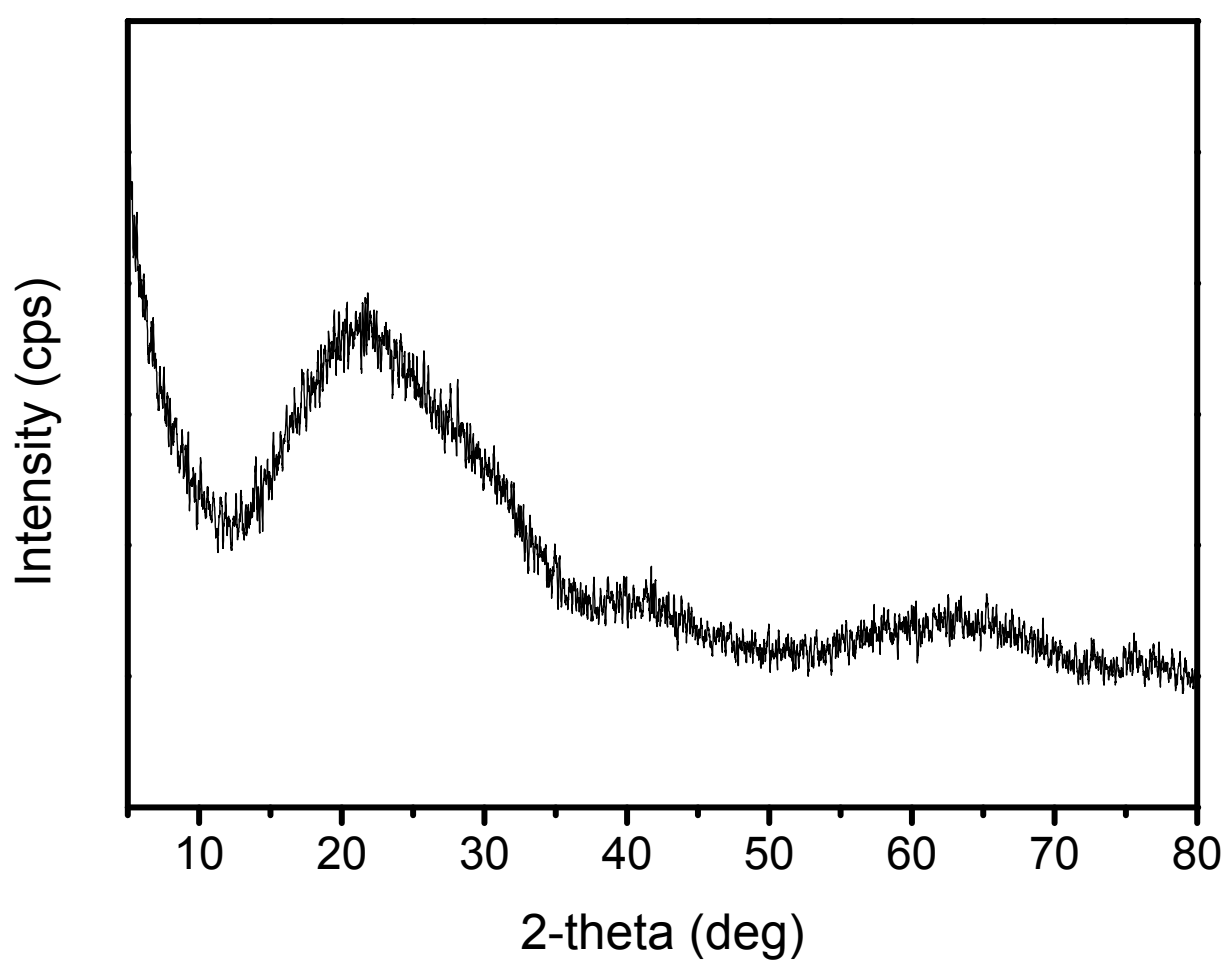

Figure S2. Powder X-ray diffraction pattern of COP-220 


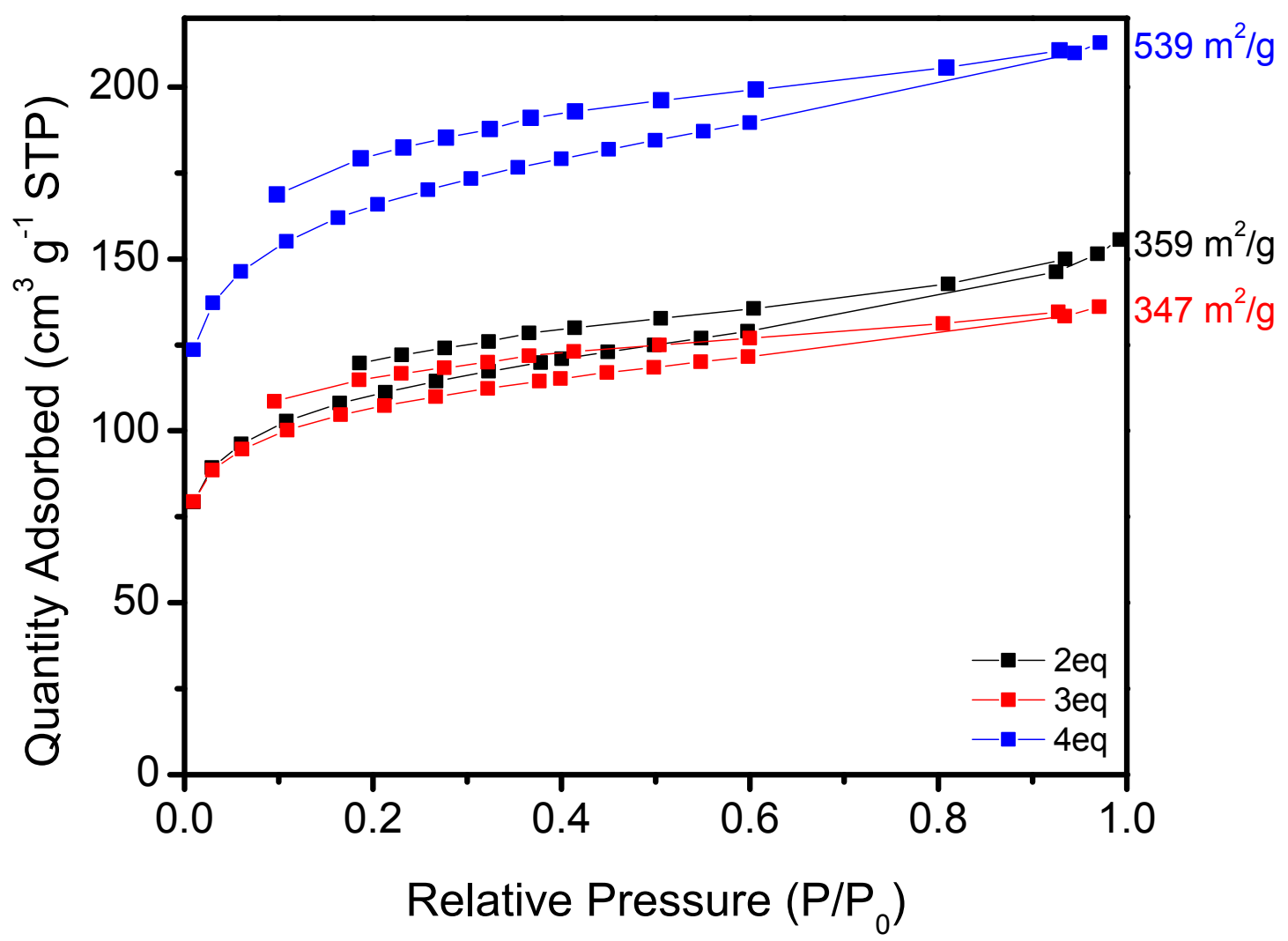

Figure S3. Argon physisorption isotherms of COP-220 at $77 \mathrm{~K}$. Relative equivalence of 1,4-diethynylbenzene compared to erythrosine B is shown: 2eq (black), 3eq (red), and 4 eq (blue). Argon gas uptake was measured at $77 \mathrm{~K}$ for better observation of microporous properties. 
a)

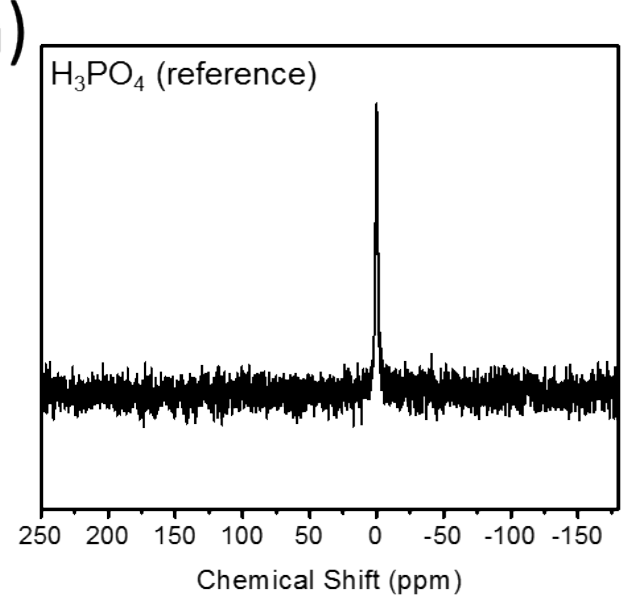

c)

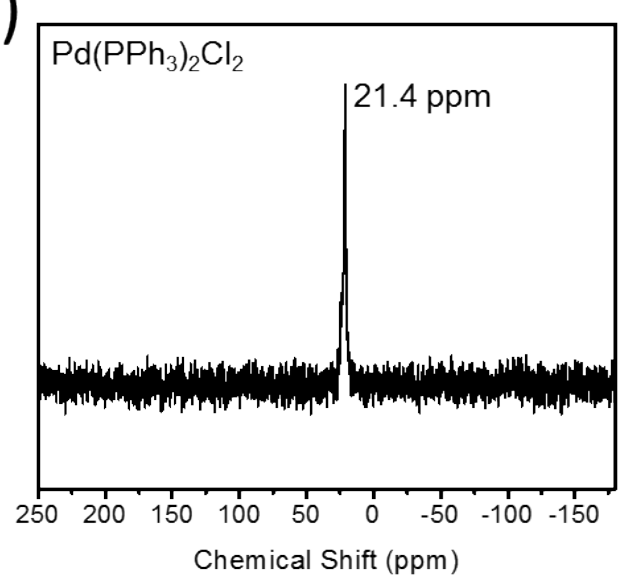

b)

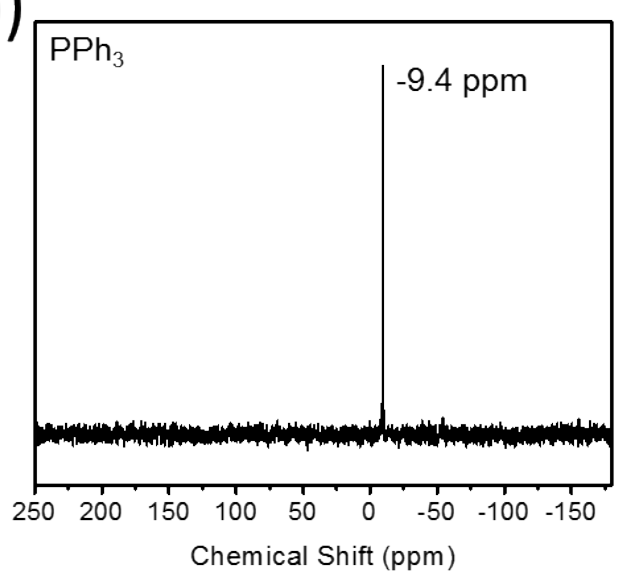

d)

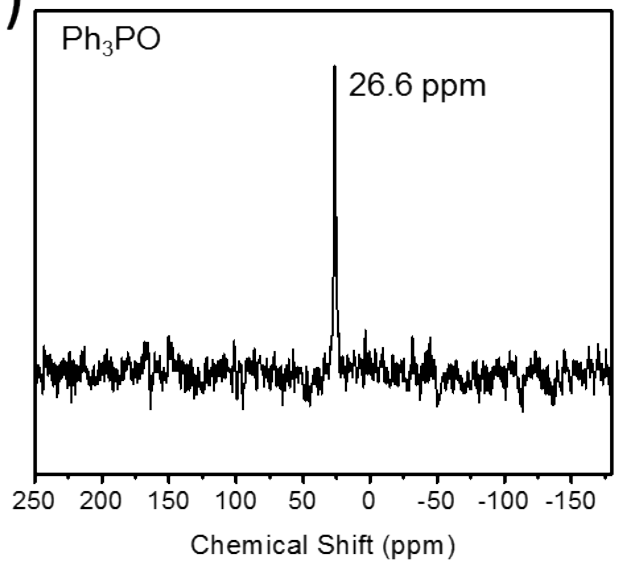

Figure S4. Solid-state ${ }^{31} \mathrm{P}$ NMR spectra of (a) phosphoric acid $\left(\mathrm{H}_{3} \mathrm{PO}_{4}\right)$ as a reference, (b) triphenylphosphine $\left(\mathrm{PPh}_{3}\right)$, (c) bis(triphenylphosphine)palladium(II) dichloride $\left(\mathrm{Pd}\left(\mathrm{PPh}_{3}\right)_{2} \mathrm{Cl}_{2}\right)$, and d) triphenylphosphine oxide $\left(\mathrm{Ph}_{3} \mathrm{PO}\right)$. 

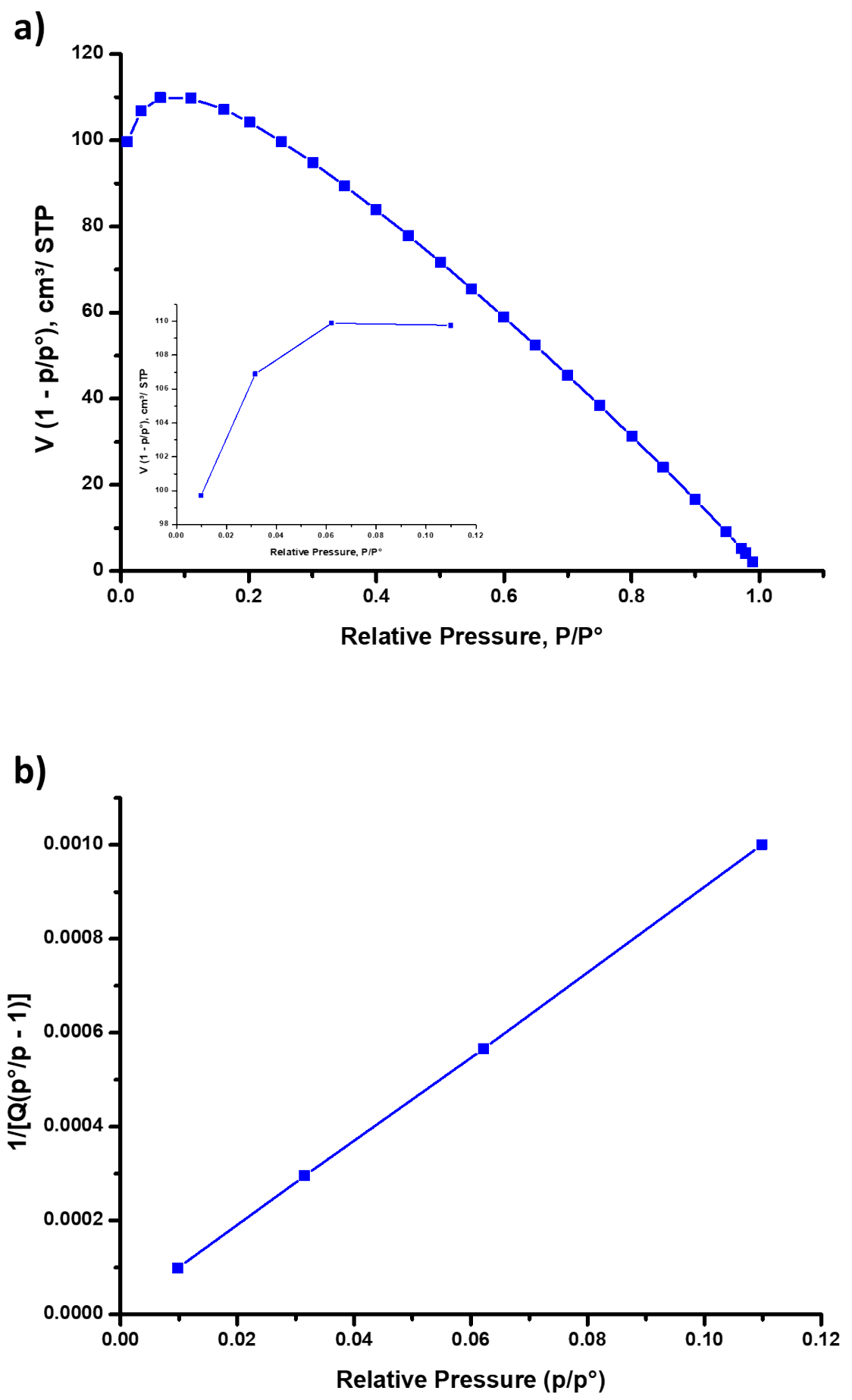

Figure S5. (a) Calculated Rouquerol plot for COP-220 (Inset: enlarged plot) along with the pressure ranges used for the BET surface area calculations. We have used the pressure range where the term $V\left(1-P / P_{0}\right)$ continuously increases with $P / P_{0}$ for the surface area calculations. (b) The selected points are located in the pressure ranges of 0.01 to 0.12 according to the Rouquerol plots. The data points are from BET plot of COP-220 obtained from nitrogen isotherms at $77 \mathrm{~K}$. 